\title{
SETE CONSIDERAÇÕES SOBRE SAÚDE E CULTURA*
}

\section{Gastão Wagner de Souza Campos**}

\begin{abstract}
RESUMO: Na perspectiva de contribuir para um modelo de atenção à saúde com bases democráticas, que leve em consideração tanto o patrimônio técnico e cultural da equipe profissional bem como o patrimônio cultural do usuário, é necessário trabalhar na saúde tendo por referência a cultura, buscando uma síntese entre o saber técnico, que valoriza a sobrevivência, com o interesse e o desejo das pessoas atendidas. Para tanto, deve-se considerar nos seguintes aspectos: o papel da cultura nas práticas da saúde o de que a cultura é um atributo humano, ela é uma construção histórica, é disciplinadora, é a institucionalização dos modos de viver a vida, de que há diferentes e heterogêneas culturas, seja entre profissionais e usuários, seja entre os próprios usuários, e que há que se estabelecer contato entre a cultura 'sanitária' dos profissionais da saúde com a das pessoas, dos usuários.
\end{abstract}

PALAVRAS-CHAVE: saúde, cultura, sanitarismo, norma, desejo

\footnotetext{
* Apresentado na Mesa Redonda: Saúde, Cultura e Democracia, em 01/10/01, no VII Congresso Paulista de Saúde Pública.

** Professor da Faculdade de Ciências Médicas da UNICAMP.
} 


\section{INTRODUÇÃO}

Eu queria agradecer o convite por duas razões: a primeira é que a Associação Paulista de Saúde Pública é um dos lugares onde eu me sinto em casa, onde eu me sinto confortável; tem lugar que a gente é estrangeiro, vendo conhecidos, amigos, tanta história juntos, tanta coisa rolando, os sanitaristas... A segunda é estar na Mesa com o Moacyr Scliar, que é meu referencial literário, meu estimulador, então para mim é uma grande honra estar partilhando a Mesa com esse grande escritor brasileiro. Eu preparei sete pontos que eu queria comentar com vocês, sobre saúde e cultura; como o sete é a conta do mentiroso e cultura é mito, então eu já vou falar uma. Esses sete pontos, estão ligados ao método, o jeito 'paidéia' de pensar.

\section{A CULTURA COMO ATRIBUTO HUMANO}

Quando a gente está metido na prática, nós sanitaristas, profissionais de saúde, é muito importante não perdermos a perspectiva de trabalhar com conceitos, com a história, essa série de coisas; nós não estamos inventando a roda agora, e o primeiro ponto que eu queria trabalhar com vocês é essa coisa da cultura e da dialética, e aí eu me lembro de uma frase que é o seguinte: acusam o velho Karl Marx de ser muito materialista, ele era mesmo, de ser muito economicista, mas tem uma frase dele que dizia o seguinte: "Olha, o Oráculo de Delfos" - aquela pitonisa, a Mãe Menininha da Grécia antiga lá - "era uma força material na Grécia antiga, tão importante quanto a economia escravista", porque ela definia um monte de coisas. Então a primeira coisa que eu quero dizer é o seguinte, os conceitos, as teorias, os valores têm força material; a gente organiza a vida, a gente intervém sobre o mundo. Quando a gente fala de cultura e saúde, nós estamos falando de atributo humano, de um atributo das pessoas, e a cultura produz pessoas, produz o jeito que nós somos, a forma que nós atuamos. Por outro lado, nós também somos produtores de cultura.

Então o primeiro ponto que eu queria marcar com vocês é que tanto a cultura quanto a saúde, elas determinam a nossa existência, a forma que somos, o jeito de ser; só que a cultura é produzida às vezes ao longo de séculos, às vezes com muita dificuldade, mas é sempre um produto humano, é coisa de gente, é coisa das pessoas, é coisa nossa. Então quando a gente pensa em cultura e saúde, tem um terceiro elemento que está sempre 
presente aí, que eu acho importante considerar, que são as pessoas. Nós somos produto dessa cultura preventivista e clínica e médica, mas nós produzimos essa cultura e reproduzimos e reconstruímos. Nós somos influenciados, condicionados pelas várias culturas, pelas várias forças, mas nós também somos capazes de reagir, de interagir, de coproduzir, de reproduzir, de modificar essa força cultural que atua sobre nós. A mãe produz a criança e a criança produz a mãe, não tem mãe sem filho e filha, e não tem filho sem mãe, enfim, essa velha coisa da dialética.

\section{CULTURA E SOCIABILIDADE}

O segundo ponto que eu queria comentar com vocês é como a cultura tem sido pensada no século XX. O quê que é cultura, quê negócio é esse? É um conjunto de valores, de costumes, de regras, de leis, que interferem em vários aspectos da nossa vida; isso tem vários autores... mas cultura é isso, é um conjunto de normas, de regras, de leis que interferem na nossa vida. Vários pensadores, alguns filósofos, o Kant, alguns sociólogos, o Durkheim e companhia, e tudo o que se seguiu depois, Positivismo, Neo-Positivismo, têm pensado a cultura como um conjunto de normas, de regras, que facilita às pessoas criar sociabilidade, viver junto. Então é comum a gente pegar autores que dizem o seguinte: "Se não tiver cultura, a gente vira o lobo do homem", ou seja, que a cultura é um conjunto de regras que serve, de quê? Disciplinando a nossa sexualidade, disciplinando as nossas paixões, disciplinando o nosso apetite, permite que a gente viva em sociedade, e o ser humano depende um do outro, a gente tende a viver... tem vários tipos de sociedade, mas a gente tende a se juntar para fazer coisas para sobreviver, e isso de se juntar, que é a sociabilidade, depende de regra, depende de um se defender do outro. Então a cultura é vista como uma força controladora, disciplinadora. Tem um famoso artigo do Freud que não lembro o nome, mas que ele trata do mal-estar que a civilização, que a cultura provoca; o quê é que o Freud coloca com muita inteligência? Ele foi um pouco além do que o Kant, falou "que esse controle, essa disciplina do instinto, da sexualidade, do interesse, do desejo de cada um provoca mal-estar nas pessoas"; o Freud dizia o seguinte: "Tudo bem, a gente renuncia, até para aceitar as regras a gente renuncia a um monte de coisas, só que depois vem a ressaca". Ele não usou esse termo não, mas eu estou adaptando, ou seja, toda renúncia provoca uma certa ressaca, que é o tal do mal-estar. Então esse é um pouco o sentido da cultura, e a saúde é um pedaço dessa cultura, nós pensamos a saúde como essa coisa que vai 
disciplinar, que vai controlar o desejo, o interesse das pessoas em função de objetivos da saúde.

\section{CULTURA E PRAZER}

O terceiro ponto que eu queria comentar é o seguinte: pensando 'paideísticamente' sobre cultura; será que cultura é renúncia, será que cultura é controle, será que é só isso? E comecei a pensar o seguinte, que cultura, na verdade, eu acho que é uma cristalização, uma institucionalização de modos considerados legítimos de viver a vida, ou seja, a cultura não cobra só renúncia, a cultura diz quais são os modos legítimos para ter prazer, para gozar, para defender o próprio interesse, ou seja, cada cultura cria modos legítimos e ilegítimos: carne de porco pode ou não pode, sexo pode em tal e tal lugar, de tal e tal forma, com tal e tal regra, com tal e tal... Então, o quê que a cultura faz? É mais do que exigir renúncia, e controle e mal-estar, a cultura cristaliza, ela legitima modos da gente lidar com o nosso desejo e com nosso interesse. Eu tenho procurado diferenciar desejo de interesse, são duas forças motoras do ser humano, dos indivíduos, dos grupos da sociedade - desejo é uma força motora para nós, eu tenho ressaltado que está muito ligado ao prazer, ao gozo, não só à sexualidade mas ao prazer de uma forma geral, e interesse está ligado à sobrevivência do indivíduo ou dos grupos: sobrevivência biológica, sobrevivência da classe, sobrevivência do grupo, do interesse. $O$ quê que a cultura faz? Ela vem e regulamenta 0 exercício desse desejo ou desse interesse. Ou seja, cultura por um lado é renúncia, por um lado é controle; qual é o modo legítimo? Para lidar com interesses ela põe limites, mas ao mesmo tempo ela autoriza, então ao mesmo tempo que fala em renúncia diz: "assim pode". Outra coisa importante nessa forma 'paidéia' está muito na moda agora, com Maturana, Varela, Teoria de Sistemas, Construtivismo aplicado, nós ficamos perto dos bichos, tudo é sistema que funciona, autopoese todo mundo, todo mundo se auto produz, e eu tenho pensado muito na diferença que existe entre a sociedade humana e a sociedade animal. Alguns disseram que era o trabalho, mas eu acho que não é o trabalho, principalmente pensando no Brasil, que a gente não gosta muito de trabalhar, mas o quê que marca a diferença de uma sociedade humana da sociedade animal? Eu acho que é a cultura, é a cultura, aí eu, pensando com vocês: vocês já viram alguma colmeia decorada? O quê que eu quero dizer com cultura? Eu quero dizer o seguinte: nós humanos pegamos o nosso instinto, o nosso desejo, tanto na perspectiva do prazer quanto na perspectiva da 
sobrevivência, do interesse, e recobrimos de cultura; então a gente tem o instinto de matar a sede, é um instinto biológico de sobrevivência, só que nós fomos matando a sede usando copo, taça, tomando bebida gelada, misturando com álcool, fazendo uma cerimônia; a gente mantém o instinto da sexualidade, da reprodução, do acasalamento, só que fomos fazendo isso com regras, com ritos de passagem, com ganhar o favor do companheiro, etc. Então uma característica humana muito marcada é de recobrir o desejo e o interesse de cultura, por isso que eu brinquei com vocês: Vocês já viram uma colmeia decorada? A gente constrói casa, vocês já viram estilo colonial de casa de formiga, estilo neoclássico? Não tem, ou seja, nós fomos combinando nosso desejo e o nosso interesse revestindo isso de cultura, e isso é uma diferença muito marcada entre o ser humano e o animal.

\section{SAÚDE E CULTURA}

O quarto ponto... começar a falar de saúde; qual é a ligação entre saúde e cultura? Uma é que a saúde, é um traço cultural, os valores, as concepções que nós temos sobre saúde são sempre um traço cultural, e a saúde está ligada a essas duas perspectivas. A medicina e a saúde pública, nós pensamos saúde muito na perspectiva da sobrevivência, anos de vida ganhos, defender a vida. Mas, do ponto de vista cultural, vida é também ligada ao prazer, ou seja, vida é também ligada à intensidade da vida, é também ligada à qualidade de vida. Então a saúde, quando a gente trata de saúde, e a cultura, procuramos regulamentar isso através da cultura, a gente tem um paradoxo que é o seguinte: quando a saúde valoriza muito a segurança, o interesse de sobreviver, nós sacrificamos a intensidade de viver; quando a gente joga muito no gozo e no desejo, a gente se queima feito uma tocha viva, tipo Jimmy Hendrix da vida e outros, e nós vivemos nesse paradoxo. E uma outra característica da cultura humana é que a cultura é um conjunto de valores, mas como o ser humano não é trouxa, não é idealista, toda vez que a gente cria uma série de contextos nós criamos junto instituições, organizações, ações organizadas humanas para garantir a reprodução e a produção dessa cultura, então não tem nenhuma cultura que não trata de escrever a Bíblia, de fazer ministro, sacerdote, Constituição, leis, regras, guardiões, etc., etc., e a saúde, como um pedaço da cultura, nós também tratamos de montar instituições que vão procurar influenciar, não só receber influência da cultura, mas influenciar a cultura no sentido que a saúde, que os guardiões da saúde, da saúde coletiva, da medicina, da clínica, etc., achamos que isso deve ser. Então a saúde, ao longo da história, tem inventado instituições: Sistema 
Único de Saúde, o sacerdote, o gurú, o médico, o sanitarista, etc., e as suas instituições e conhecimentos, ou seja, aparelhos especializados encarregados de cuidar da saúde, de produzir saúde, de interferir nos valores culturais tradicionais em nome da defesa da vida, em geral nessa perspectiva mais quantitativa, anos de vida.

\section{A HETEROGENEIDADE DA CULTURA}

Quinto ponto... eu queria voltar um pouquinho à coisa da cultura e pensar a cultura hoje, pensar um pouco esse negócio da cultura hoje. A cultura, mesmo quando Freud fala de cultura, tem texto do Freud em que está colocado mal-estar, está traduzido mal-estar na cultura, tem outros textos que estão traduzidos como mal-estar na civilização, então uma série de autores tomaram esse conceito de cultura como de civilização, o tal do etnocentrismo. Os antropólogos no século passado, no século XX, pegaram essa concepção etnocêntrica e caíram matando, criticaram, quebraram, ou seja, o que é a concepção etnocêntrica? É criticar outra cultura, outro conjunto de valores com critérios referentes a uma cultura própria.

Então quando a gente fala em cultura hoje, nós temos que estar de acordo com essa concepção que o Fernando Abreu, aqui dizendo, que existem culturas diferentes, existem conjuntos de valores, existem conjuntos de formas de lidar com o desejo e o interesse é bastante heterogêneo, é bastante diferente nas diversas sociedades. Pensando a cultura hoje, o quê que eu queria refletir com vocês? É que existem algumas sociedades que têm culturas mais homogêneas, existem algumas sociedades que têm culturas mais heterogêneas, e aí eu começo a ligar o tema da democracia, que é o terceiro assunto que eu não falei até agora, mas como eu estou num Congresso de Saúde Pública... Tradição do Oswaldo Cruz. Mas tem cultura mais homogênea e cultura mais heterogênea. Quando eu fiz Residência em Clínica Médica, comecei a mexer com tuberculose, a mesma história, eu tinha vontade de... no começo da minha vida eu me inspirava em São Francisco, depois no Che Guevara, mas enfim, essa coisa... e hoje no Moacyr (risos), enfim, eu fui me acalmando ao longo da vida. (em off, Moacyr Scliar comenta : "É o único que está vivo desses três"). Dos três, pois é... preocupado com a saúde nas suas duas dimensões. Mas o quê que eu quero dizer com isso é o seguinte, eu fazia Residência e não tinha feito serviço militar, eu fazia em Brasília, e aí sexta e sábado a gente era obrigado, quem servia... eu servia, entrei na FAB, nas Unidades Aéreas Sanitárias, criadas pelo Noel Nultz, que é um brilhante livro 
que o Moacyr escreveu, quem não leu pode ler, incrível, é um romance realista, e eu trabalhava nessa Unidade Sanitária. Chegava sexta-feira a gente ia para a reserva Xavantes atender os índios, e eu fiquei impressionado, naquela época, falando de 25 anos atrás, eu fiquei impressionado com o grau de homogeneidade da cultura daquele povo. Eram reservas, aldeias que tinham muito pouco contato com o ser humano, então não tinham tido um contato muito grande com a nossa civilização. Enfim, tinham tido pouco contato com a civilização ocidental, que nós consideramos seres humanos. Eu fiquei muito impressionado, numa cultura homogênea - é porque eu vou falar uma coisa politicamente incorreta, já comecei sendo politicamente incorreto - eu fiquei impressionado negativamente, e na época estava aparecendo a cultura alternativa, a gente criticava a nossa cultura ocidental, eu fiquei muito impressionado com o comportamento estereotipado que a maioria dos índios tinha. $\mathrm{Na}$ época a gente era rebelde, depois de 68 a gente tinha acostumado a criticar a tradição, o passado, a gente vivia disso, era insuportável pensar que os antepassados, que a tradição sempre tinha razão. Eu cheguei lá, a maioria dos índios viviam isso, não achavam isso não, eles viviam isso; eu não vi nenhum índio alcoolizado, eles só usavam o álcool, o álcool que eles produziam, nas cerimônias religiosas; a maioria da população indígena tinha a primeira relação sexual depois dos ritos de iniciação; a maioria das pessoas, conforme o seu papel social, se vestiam de tal ou qual forma. Então o quê que eu quero dizer? É uma sociedade em que a cultura era tão estruturada, era tão forte, era tão homogênea, que o sujeito, que as pessoas tinham um grau de autonomia, uma capacidade crítica e de proceder de forma diferenciada em relação à saúde, ao sexo, ao lazer, ao prazer, ao interesse, ao desejo de forma muito estruturada, muito semelhante. Não estou dizendo se isso é bom ou ruim, estou fazendo uma constatação.

Com o desenvolvimento industrial, com o desenvolvimento da informação, com o desenvolvimento científico, mas particularmente com o desenvolvimento da luta democrática, da luta pela cidadania, ou seja, com a liberdade de expressão e de opinião, com a idéia de que cada sujeito pode, tem um grau de autonomia, respeitando o contexto, a Constituição, o outro, etc., a maioria das sociedades foram ficando heterogêneas. Então nós convivemos nessas sociedades industrializadas, que têm vários grupos, que receberam pessoas de vários países, como é o caso do Brasil, nós convivemos com culturas bastante heterogêneas, essa heterogeneidade permite que nós tenhamos uma relação mais crítica com as várias culturas estruturadas. Se tem a cultura do preventivismo, eu posso ser mais crítico com a clínica, porque eu tenho as duas, porque nós temos as duas, então acho que isso é uma outra constatação que eu queria dizer para passar para o sexto ponto. Inclusive a tal da 
globalização, ainda no quinto ponto, ela não cria uma cultura única; dentro de uma perspectiva dialética, o que tem acontecido é que as várias culturas locais, específicas, setoriais, acabam criando sínteses específicas que ninguém consegue influir, fugir da influência da globalização, mas por outro lado ninguém, quase ninguém é um papel em branco onde vai ser escrito... nós não vamos virar norte-americanos. $O$ meu Estado, Goiás... há 25 anos atrás Goiás tinha uma cultura espanhola, portuguesa, tradicionalista, católica, caipira, etc., hoje Goiás é uma mescla de Texas, mas não é o Texas, mas óbvio que fomos influenciados pela globalizaçâo. Agora, lá, em vez de pegar Paris, em vez de pegar Miami, pegou o Texas. Por quê que lá pegou o Texas e não virou o Texas? Então o quê que quero dizer é o seguinte, nós não somos passivos frente às várias culturas, por mais potentes, por mais fortes, por mais estruturadas que eles sejam, e a luta democrática, a liberdade de expressão, esse conjunto que nós chamamos de cidadania, é uma das formas que temos para lidar com essa cultura.

\section{HISTÓRIA E CULTURA}

Então o ponto seis, para chegar no final. Na saúde pública as culturas, portanto, são construções sociais históricas, nós descobrimos isso e a gente vem procurando influir nas culturas ativamente; a propaganda é isso, quê que é a propaganda, o marketing? A educação é isso, a saúde pública faz isso, a medicina faz isso, as religiões fazem isso, ou seja, nós enfrentamos de forma ativa a cultura.

\section{NOVAS RELAÇÕES ENTRE SAÚDE E CULTURA}

Para encerrar minha fala, eu queria pegar esse referencial que eu estou construindo com vocês aqui, com alguma dificuldade e rapidez, porque o assunto é complexo, para pensar a saúde pública brasileira. Eu identifiquei que a saúde pública brasileira tem quatro modelos, quatro estilos, não é nem modelo, quatro estilos de relação com a cultura; como é que a saúde pública se relacionou com a cultura? No primeiro período, que o epígono é Oswaldo Cruz, o modelo é esse que o Moacyr já descreveu aqui, os nossos sanitaristas consideravam que a única cultura legítima era a cultura científica, era a cultura da 
microbiologia, então nem se preocupavam muito com a cultura nacional e só queriam mudar essa cultura nacional, queriam, para controlar a epidemia, para controlar a febre amarela, queriam que as pessoas vacinassem, queriam que as pessoas fossem internadas nos hospitais, queriam que a cidade fosse sanitarizada, não era saudável na época, era sanitarizada, era isso. Só que pensavam em fazer isso usando o poder legal da autoridade sanitária, o poder constrangedor da lei, dos vigilantes sanitários, da polícia, da Constituição, e usando o poder da cultura científica da época. Tem uma fase seguinte - isso foi muito analisado, eu não vou analisar, isso gerou uma série de conflitos que termina com a Revolta da Vacina.

Depois nós temos uma fase seguinte que é, eu acho, que o representante modelar disso é o Monteiro Lobato, que não era médico, mas na sua campanha do Jeca Tatu contra o amarelão, contra as verminoses, qual é a mensagem? E aí sim, começa-se a se preocupar com a cultura popular, com a cultura sanitária da população, que não é nem sanitária, é a cultura do descuido, e se usa um referencial behaviorista, condutivista, ou seja, se pensa que, através de técnicas de educação, ou seja, o ser humano é um papel em branco que através de estímulo/resposta, se a gente der um estímulo adequado, um panfleto adequado, a educação adequada, vamos ter uma resposta adequada, independente do sujeito e do seu contexto, que é o cerne do condutivismo, que é o cerne do behaviorismo. Monteiro Lobato não estudou Skiner, mas está influenciado pelo contexto; nem tampouco os sanitaristas brasileiros, depois de 30 , estudaram isso, mas a nossa educação em saúde tinha esse espírito do Monteiro Lobato, e também é muito influenciada pelo pensamento liberal clássico. Qual era o estímulo básico? O estímulo básico é o econômico. Por quê que Jeca Tatu tem que ser arrancado daí? Tem que ser arrancado daí porque ele vai ficar rico e porque o país vai ficar rico, então é o estímulo econômico, onde a racionalidade da escolha das pessoas é uma racionalidade econômica. Se a gente explicar para o Jeca Tatu, que se ele cuidar da saúde ele vai ficar rico, ele vai cuidar; se a gente explicar para o fazendeiro e para o industrial que se ele prevenir a saúde ele vai ganhar mais dinheiro, ele vai, então é a racionalidade econômica, isso não desapareceu, está presente até hoje, nós fomos acumulando essas várias formas de lidar com a cultura. Dando um grande salto, chego hoje em dia, e eu noto que a gente tem dois grandes modelos, aí minha provocação final; a promoção em saúde, principalmente a promoção à saúde de inspiração canadense, que prioriza o estilo de vida, tem parentesco muito grande, na minha opinião, com o estilo Monteiro Lobato de fazer ação de saúde. Óbvio que não é a verminose é o estilo de vida, são as doenças crônicas, que também... o estilo para isso são razões econômicas; por quê fazer 
do tabaco o grande adversário da humanidade? Porque nós vamos gastar uma fortuna tratando esse bando de enfisematosos, não sei o quê, então é uma razão econômica para os profissionais de saúde; para a população é o medo da morte: "Se vocês não pararem de fumar vocês vão todos morrer; se vocês fizerem sexo seguro vocês vão todos morrer; se vocês comerem carne vermelha vocês vão todos morrer". Então a gente usa técnicas condutivistas, neo-condutivistas, neo-behavioristas, moralistas, fundamentalistas, pouco valor ao desejo e muito valor à sobrevivência, então nós estamos retomando, através do discurso da promoção à saúde; promoção à saúde não é só isso, nós estamos retomando parte dessa cultura.

Agora, tem uma outra alternativa contemporânea, que no Brasil está materializada num outro modelo que lida com a cultura de forma muito mais dialética, interativa, considerando o interesse de sobreviver mas também o desejo, a cultura, o prazer, a realização, o sujeito e seu contexto, que no brasil está exemplificado pelo programa de controle de AIDS, de DST/AIDS. O quê esse programa traz de novo quando fala em promoção? Primeiro, as técnicas de promoção e prevenção têm que variar conforme o sujeito com quem a gente está trabalhando: se é crente, trabalha com crente; se é jovem, trabalha com jovem; se é idoso, trabalha com idoso; se é dependente de droga, trabalha com dependente de droga. O conceito de redução de dano, não como só de distribuição de seringas, mas pensando como uma combinação da cultura e técnica, aí é tanto da clínica quanto da cultura epidemiológica e sanitária; o quê que o conceito de redução de dano indica e a gente deve avançar e explorar isso? Por um lado, a gente respeita e trabalha, e nós estamos inseridos, eu não estou propondo para ninguém sair daí, sanitaristas, clínicos, enfermeiros, etc., nós sairmos da cultura técnica, clínica e sanitária, essa cultura tem que interagir, fazer contrato, fazer síntese com a cultura dessas outras pessoas, que está ligada a seu desejo, a seu interesse, à sua tradição, quando nós falamos em redução do dano é isso que nós estamos trabalhando. Então nós vamos trabalhar com o conceito epidemiológico, não é nem conceito com a evidência material de que o uso compulsivo de tabaco facilita câncer, doença cardiovascular, etc. etc.; agora isso tem que ser trabalhado da seguinte forma: "Quanto você goza com o cigarro, quanto isso é fundamental na sua vida? Dá sentido à sua vida?" Vamos mandar todos hipertensos parar de ter stress, emoção, parar de trabalhar? Eu tenho que perguntar para cada hipertenso e interagir: "A emoção é fundamental para você? Trabalho dá sentido à sua vida? Até quando? Escrever dá sentido à sua vida?”. O pobre do Érico, me lembrei do Érico Veríssimo, que os médicos falaram para ele no fim da vida, ele estava todo entupido lá, não tinham ponte de safena na época lá, disse: "Você tem 
que parar de sofrer emoção", aí ele foi escrever a autobiografia, trancado em casa. Não sei se vocês já escreveram currículum, autobiografia deve ser pior, é cada emoção, porque você lembra de tudo que não pode escrever, na derrota que teve; então é assim, o médico dessa pessoa tem que saber lidar, para o escritor lidar com isso é fundamental, o cara tem que estar agoniado, tem que estar sofrendo, tem que estar interagindo, tem que estar trabalhado.

Então nós temos no Brasil um exemplo, um outro modelo que começa a ser construído, que começa a ser, na Aids e que indica uma nova forma da saúde, da instituição saúde lidar com cultura, procurando essa síntese entre o nosso saber técnico, que valoriza a sobrevivência, com o desejo, o interesse das outras pessoas. Era isso que eu queria dizer.

\section{SEVEN CONSIDERATIONS ON HEALTH AND CULTURE}

ABSTRACT: In order to contribute to a healthcare model with democratic bases, that takes into account the technical and cultural assets of the professional team as well as the cultural assets of users, it is necessary to work on health having culture as a reference, seeking for a synthesis among technical knowledge, which values survival, and interests and wishes of people seen. Therefore, the role of culture should be considered in health practices as regards to the following aspects: culture is a human attribute; it is a historic construction; it is disciplinary; it is the institutionalization of how we live our lives; there are different and heterogeneous cultures, either among professionals and users, or among the users themselves; and it is paramount to establish contact between the "public health" culture of healthcare professionals and that of individuals, of users.

KEYWORDS: health, culture, public health, standard, wishes 